\title{
SOSIALISASI, EDUKASI SERTA BAKTI SOSIAL DALAM GERAKAN PESISIR BEBAS SAMPAH PLASTIK DI PANTAI NAGA PERMAI GAMPONG SUAK PUNTONG KECAMATAN KUALA PESISIR KABUPATEN NAGAN RAYA
}

\section{SOCIALIZATION, EDUCATION WITH SOCIAL WORK IN THE MOVEMENT OF PLASTIC WASTE IN THE NAGA PERMAI COASTAL, SUAK PUNTONG VILLAGE, KUALA PESISIR SUB-DISTRICT NAGAN RAYA DISTRICT}

\author{
Nabil Zurba ${ }^{1 *}$, Yulie Rahayu Fitrianingsih ${ }^{1}$, Muhammad Arif Nasution ${ }^{1}$, Neneng Marlian ${ }^{1}$ \\ ${ }^{1}$ Prodi Sumberdaya Akuatik Fakultas Perikanan dan IImu Kelautan Universitas Teuku Umar \\ *Korespondensi: nabilzurba@utu.ac.id
}

\begin{abstract}
ABSTRAK
Salah satu objek wisata yang ramai dikunjungi di Kabupaten Nagan Raya adalah kawasan pantai Naga Permai. Panorama alam yang indah membuat kawasan pantai Naga Permai memiliki daya tarik wisata. Tingginya jumlah wisatawan yang berkunjung ke kawasan pantai Naga Permai dapat menimbulkan dampak negatif berupa limbah wisata berupa sampah plastik yang berpotensi menurunkan kualitas lingkungan dan kelestarian lingkungan kawasan pantai Naga Permai. Limbah wisata berupa sampah plastik hasil kegiatan wisata yang bersumber dari wisatawan dan pelaku usaha wisata. Tujuan kegiatan ini adalah memberikan sosialisasi Mensosialisasikan pentingnya mengelola sampah dengan baik, memilah sampah plastik dan non plastik, serta memberikan gambaran akibat yang akan timbul di kemudian hari apabila sampah plastik tidak terkontrol dan Memberikan contoh langsung kepada masyarakat cara memilah sampah dan mencontohkan agar tidak membuang sampah ketika berwisata. Pengabdian ini akan dilakukan menggunakan metode pendekatan dengan metode ceramah/pendampingan. Sedangkan tahapan untuk menyelesaikan permasalahan tersebut dengan melakukan contoh bakti sosial. Luaran yang didapat adalah Timbulnya kesadaran dan inisiatif dari pemilik café dan pengunjung agar tidak membuang sampah plastik sembarangan.
\end{abstract}

Kata Kunci : Naga Permai, Wisata, Sampah Plastik

\begin{abstract}
One of the most visited attractions in Nagan Raya Regency is the Naga Permai beach area. Beautiful natural panorama makes the Naga Permai beach area has a tourist attraction. The high number of tourists visiting the Naga Permai beach area can have a negative impact in the form of tourism waste in the form of plastic waste which has the potential to reduce the environmental quality and environmental sustainability of the Naga Permai beach area. Tourism waste in the form of plastic waste from tourist activities sourced from tourists and tourism businesses. Purpose This activity is providing socialization. Socializing the importance of managing waste properly, sorting out plastic and non-plastic waste, as well as providing an overview of the consequences that will arise in the future if plastic waste is not controlled, and providing direct examples to the community on how to sort out garbage and exemplify so as not to dispose of waste when traveled. This service will be done using the approach method with the lecture / accompaniment method. While the stages to solve these problems by doing examples of social service. The output obtained is the emergence of awareness and initiative from café owners and visitors so as not to litter plastic.
\end{abstract}

Keyword : Naga Permai, Tourism, Plastic Waste 


\section{PENDAHULUAN}

Aceh merupakan salah satu Provinsi yang memiliki potensi pariwisata yang besar, tersebar dari Pulau Sabang sampai Pulau Banyak dengan kekayaan geografis, sosial budaya, dan adat istiadat. Potensi kekayaan dan keragaman sosial budaya serta berbagai potensi alam yang dimiliki Provinsi Aceh merupakan modal utama bagi pengembangan sektor pariwisata yang diharapkan mampu menjadi sektor unggulan sehingga meningkatkan perekonomian Aceh secara keseluruhan. Berdasarkan data dari Kementerian Pariwisata dan Ekonomi Kreatif tahun 2016, sektor pariwisata merupakan salah satu komoditas ekspor dari 12 jenis komoditas unggulan penyumbang devisa bagi perekonomian Indonesia.

Salah satu alasan penetapan pantai Naga Permai sebagai salah satu destinasi prioritas pariwisata Kabupaten Nagan Raya adalah karena keunikan alam yang dimiliki kawasan Laut berpasir yaitu hamparan pasir yang mengelilingi wilayah gampong Suak Puntong. pengelola pantai Naga Permai telah mengembangkan kawasan pantai menjadi beberapa wahana wisata dengan sarana dan prasarana yang telah dibangun seperti café, gazebo dan kolam renang bagi anak anak.

Berdasarkan Peraturan Pemerintah Republik Indonesia Nomor 81 Tahun 2012 mengenai pengelolaan sampah rumah tangga dan sampah sejenis rumah tangga, perlu dikembangkan pengelolaan sampah yang berprinsip pada 3R (reuse, reduce, recycle), namun pada pelaksanaannya dibutuhkan sejumlah biaya untuk pengadaan dan operasional untuk pengelolaan sampah dari kegiatan wisata di kawasan Pantai Naga Permai. Adanya pengadaan pengelolaan sampah dikawasan Pantai Naga Permai dibutuhkan partisipasi masyarakat yaitu wisatawan dan pelaku usaha yang melakukan kegiatan wisata di kawasan pesisir pantai untuk menjaga kebersihan kawasan.

\section{Permasalahan}

Salah satu permasalahan lingkungan di kawasan wisata adalah limbah yang dihasilkan dari kegiatan wisata terutama sampah plastik. Sampah plastik dari kegiatan wisata yang berada di pantai Naga Permai menjadi masalah yang perlu ditangani, adanya kegiatan wisata dan peningkatan jumlah wisatawan yang berkunjung ke kawasan tersebut berpotensi penurunan fungsi lingkungan dan fungsi wisata di kawasan pantai Naga Permai. Tingginya jumlah wisatawan dan kegiatan wisata yang tidak sustainable dapat menimbulkan permasalahan lingkungan di masa yang akan datang. Sustainable dalam kegiatan wisata adalah proses dimana suatu kegiatan wisata mencukupi kebutuhan wisata generasi sekarang tidak boleh mengurangi kemampuan generasi-generasi mendatang untuk memenuhi kebutuhannya sendiri terhadap wisata.

Sampah plastik yang diakibatkan oleh aktivitas wisata harus dapat dikelola dengan baik. Limbah wisata yang tidak dikelola dengan baik akan menurunkan daya tarik wisata karena dapat menurunkan kualitas lingkungan dan kelestarian suatu kawasan yang akan berpengaruh terhadap jumlah kunjungan. Demikian pula halnya dengan wisata alam di pantai Naga Permai yang akan mengalami penurunan kualitas dan kelestarian lingkungan bahkan kerusakan lingkungan akan terjadi apabila upaya pengelolaan sampah dari kegiatan wisata tidak dilakukan dengan baik, sehingga akan 
dapat menghilangkan kegiatan wisata di kawasan tersebut dan akan menghilangkan manfaat ekonomi bagi masyarakat sekitar kawasan.

\section{Tujuan Pelaksanaan}

Adapun tujuan pelaksanan kegiatan pengapdian kepada masyarakat ini adalah:

1. Meningkatkan kesadaran wisatawan dan pemilik usaha dalam mengurangi dan mengelola sampah plastik di sekitar objek wisata.

2. Memonitoring dan memunggut sampah dari kegiatan wisata yang dapat merusak keindahan objek wisata dan merusak lingkungan.

\section{METODE PELAKSANAAN}

\section{Tempat dan Waktu}

Pelaksanaan ini dilakukan pada tanggal 6 Oktober 2019 di Pantai Naga Permai, kecamatan Kuala Pesisir Kabupaten Nagan Raya. Tepatnya kepada wisatawan dan pemilik kafe di sekitar Pantai Naga Permai.

\section{Tahap pelaksanaan}

Pengabdian ini akan dilakukan menggunakan metode pendekatan dengan metode ceramah/pendampingan. Sedangkan tahapan untuk menyelesaikan permasalahan tersebut dengan melakukan contoh bakti sosial, tahapannya adalah sebagai berikut:

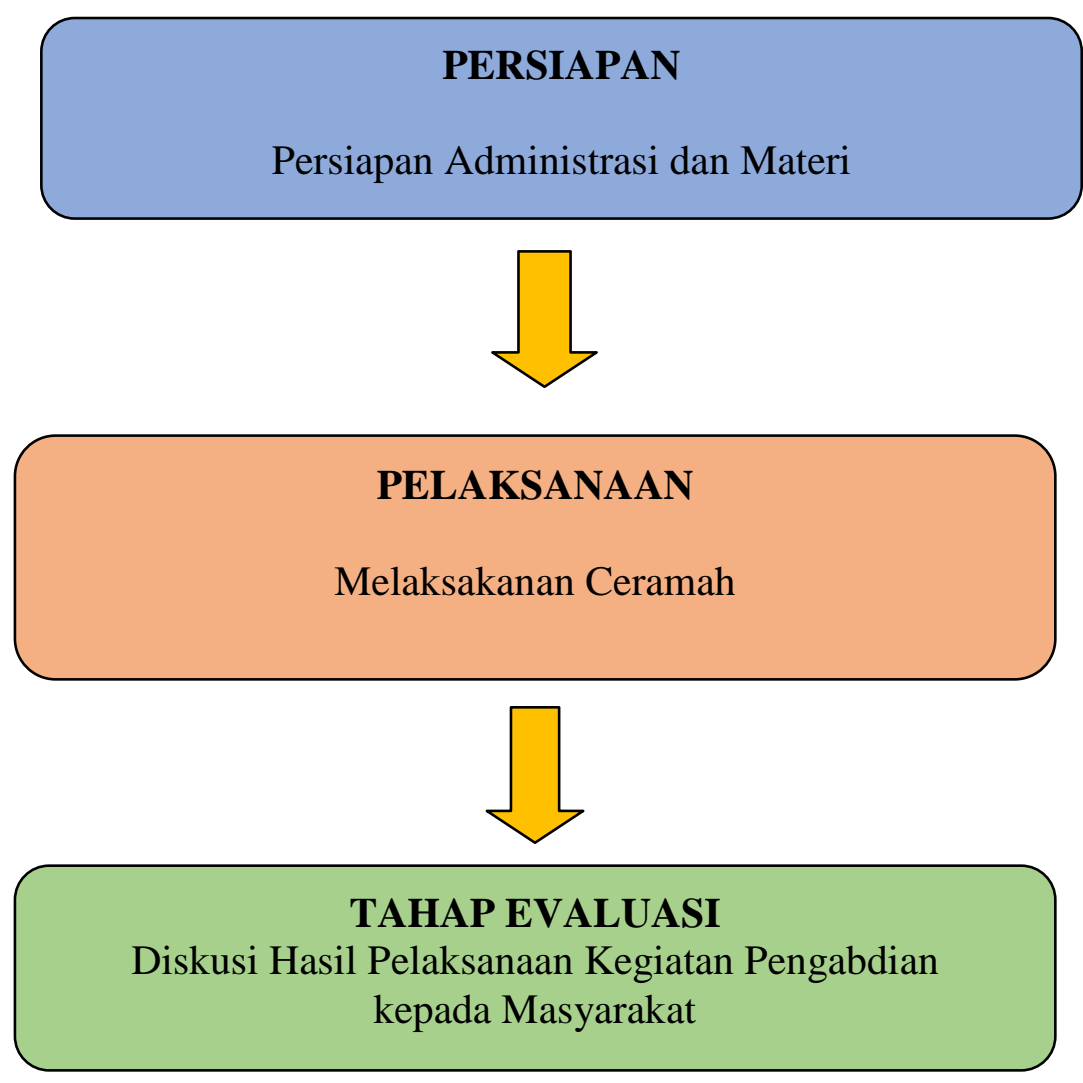




\section{HASIL DAN PEMBAHASAN}

\section{Kegiatan pendidikan kesehatan (penyuluhan)}

Kegiatan dimulai dari pembukaan dan perkenalan kepada masyarakat yaitu pemilik usaha dan wisatawan di pantai Naga Permai yang menjadi sasaran kegiatan. Kemudian dilanjutkan dengan materi penyuluhan mengenai pengertian sampah plastik baik yang berukuran besar ataupun microplastik dan dampak yang di timbulkan bagi ekosistem pesisir dan nilai estetika dari pantai tersebut.

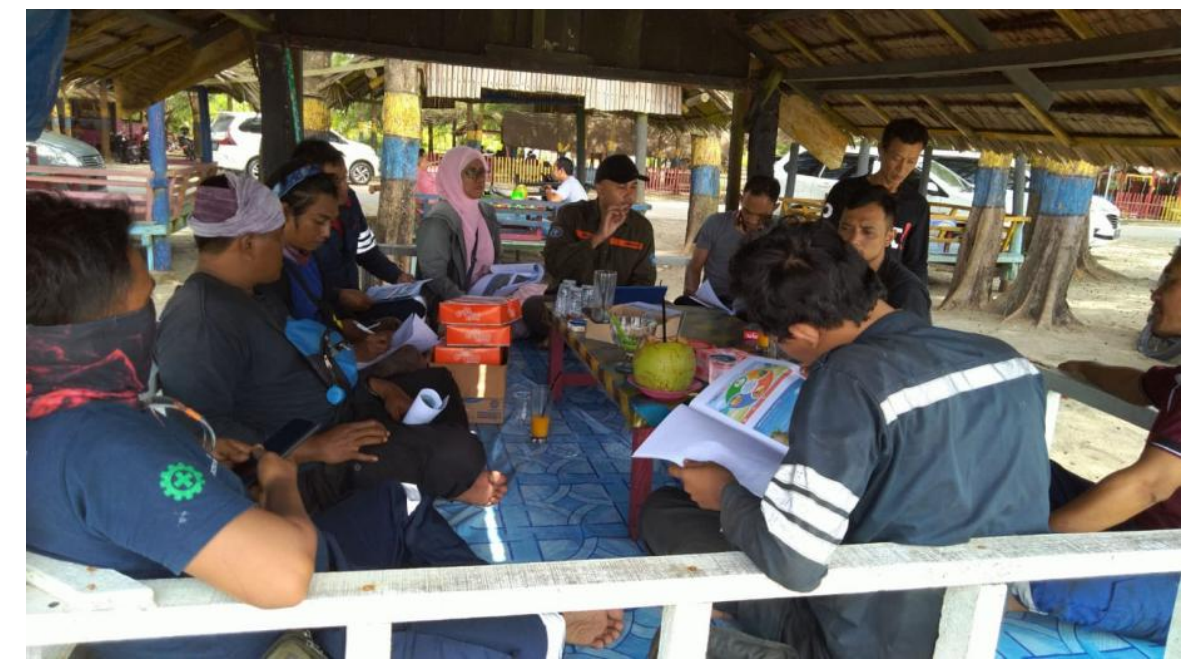

Gambar 1. Sosialisasi tentang pentingnya menjaga kebersihan pantai dari sampah plastic kepada wisatawan.

Bagian pamungkas dari kegiatan pengabdian ini adalah sesi diskusi/tanya jawab dengan peserta penyuluhan mengenai dampak yang ditimbulkan dari mikroplastik tersebut dan kegiatan apa yang harus dilakukkan sebagai solusi dari permasalahan tersebut.

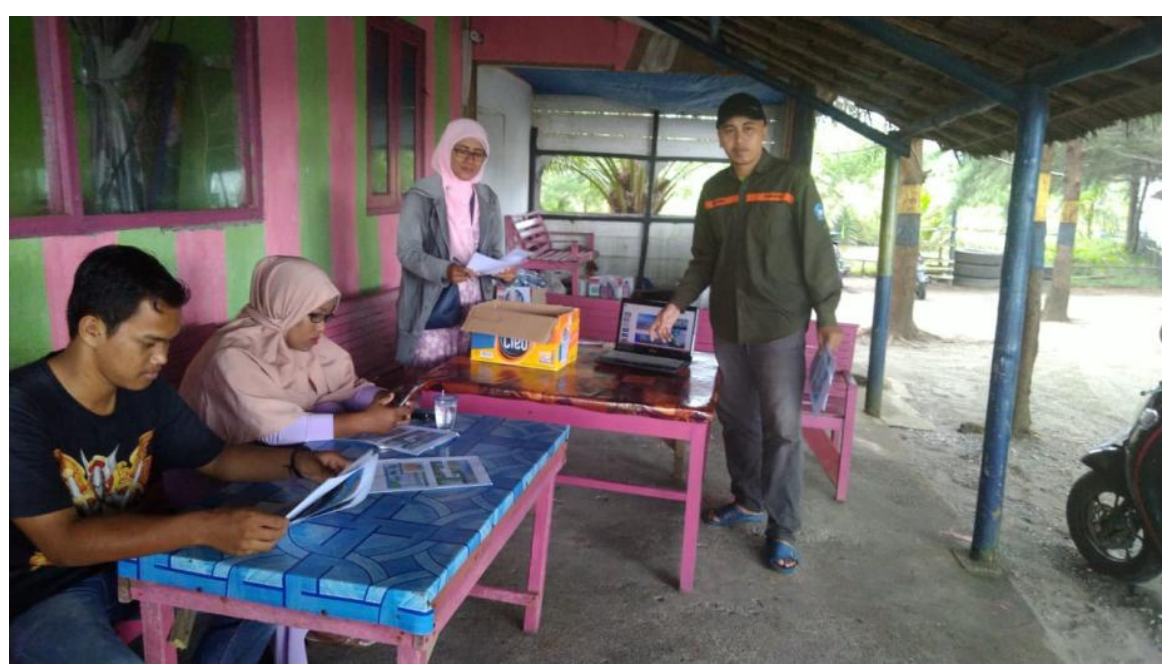

Gambar 2. Sosialisasi tentang pentingnya menjaga kebersihan pantai dari sampah plastik kepada pemilik kafe. 
Kegiatan mengaplikasikan materi penyuluhan dalam bentuk bakti sosial Setelah mendapat pembekalan ilmu dalam materi penyuluhan tentang bahaya sampah plastik dan cara untuk mengatasi masalah sampah plastik yang ada dipesisir pantai, maka tim penyuluhan memberi contoh bagaimana memunggut dan memilah plastik yang akan diambil dari pantai

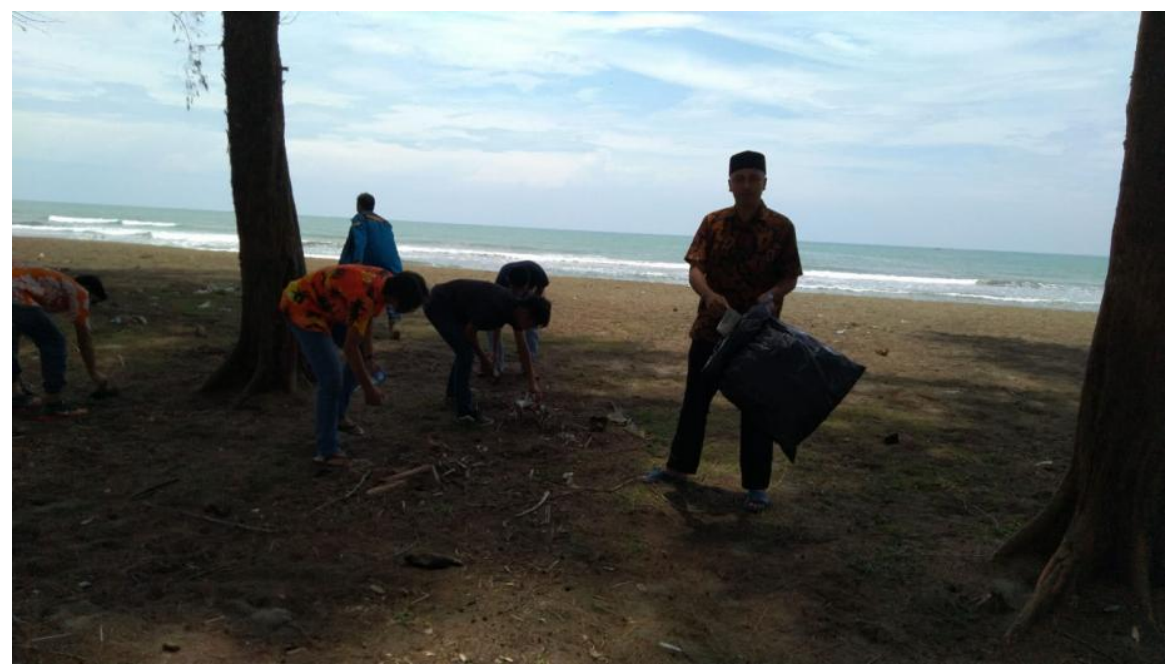

Gambar 3. Pemungutan dan pemilahan sampah di pesisir pantai Naga Permai.

Perlunya memilah antara sampah organik dan anorganik seperti plastik akan memudahkan dalam penanganan sampah tersebut. Penanganan sampah organik berupa daun kering dan kulit kelapa muda dapat di timbun didalam tanah yang bermanfaat bagi kesuburan tanah dimasa yang akan datang. Sedangkan pengelolaan sampah plastik dapat dilakukan dengan cara dikumpulkan secara terpisah kemudian dibuang kedalam tempat sampah yang disediakan khusus untuk sampah plastik, dapat juga diberikan kepada pengepul plastik untuk didaur ulang.

\section{Luaran Kegiatan yang didapatkan diantaranya adalah:}

1. Dengan adanya program pengabdian masyarakat yang berupa penyuluhan mengenai manajemen pembuangan sampah yang baik ini diharapkan dapat meningkatkan pengetahuan masyarakat tentang pengertian sampah, karakteristik sampah di dipesisir, pengelolaan sampah, perencanaan pengelolaan sampah yang baik dan benar di pesisir. Selain itu diharapkan semakin meningkatkan kesadaran Masyarakat akan bahaya yang bisa ditimbulkan akibat tidak membuang sampah ditempatnya.

2. Lebih jauh, diharapkan kegiatan-kegiatan serupa dapat berdampak pada peningkatan kesadaran masyarakat Pesisir di Nagan Raya, khususnya pada masyarakat sebagai Stake holder utama agar ikut aktif menjaga kebersihan dan kesehatan lingkungan.

3. Universitas Teuku Umar, khususnya Fakultas Perikanan dan IImu Kelautan semakin dikenal sebagai institusi yang mempunyai kepedulian terhadap permasalahan masyarakat khususnya tentang kebersihan Lingkungan. 


\section{PENUTUP}

\section{Kesimpulan}

1. Masyarakat diberikan pendidikan (penyuluhan) mengenai pentingnya menjaga lingkungan pesisir dari sampah plastik dan mikroplastik.

2. Dari hasil penyuluhan, masyarakat memahami mengenai isi materi dan di akhir sesi diberikan waktu tanya jawab. Didapatkan beberapa pertanyaan dari masyarakat diantaranya: a. Bagaimanakah cara membedakan sampah plastik dan mikro plastik? b. Bagaimana cara mendaur ulang sampah agar bermanfaat? c. Bagaimana sebaiknya bentuk tempat sampah yang baik?

3. Untuk mengevaluasi tingkat pemahaman masyarakat terhadap isi materi penyuluhan, maka diberikan beberapa pertanyaan terkait isi materi penyuluhan dan masyarakat dipersilahkan untuk menjawab. masyarakat yang berhasil menjawab pertanyaan dengan benar diberikan door prize sebagai tanda apresiasi.

\section{Saran}

1. Perlunya kegiatan rutin dalam memonitoring aktivitas pengelolaan sampah di Lingkungan Pesisir Naga Permai agar di ketahui perkembangan secara time series

2. Serta diperlukan sistem pengelolaan sampah yang ramah lingkungan. Agar pengelolaan sampah dapat terintegrasi dengan baik terhadap ekosistem pesisir.

\section{UCAPAN TERIMA KASIH}

1. Tim Pengabdian Prodi SDA mengucapkan terima kasih Pemilik kafe yang memfasilitasi kegiatan ini dan para wisatawan yang antusias dalam kegiatan pengabdian ini.

2. Tim Pengabdian Prodi SDA juga mengucapkan terima kasih kepada Keuchik dan Aparatur Gampong Suak Puntong, Kecamatan Kuala Pesisir, Kabupaten Nagan Raya yang membantu dalam memberikan izin dan aksestabilitas dalam kegiatan pengabdian ini. 